\title{
The Norwegian action plan on short-lived climate pollutants
}

\author{
V. Vestreng, M. M. Kvalevåg, S. Guttu \& S. Figenschau Skjellum \\ Climate Department, Norwegian Environment Agency, Norway
}

\begin{abstract}
Short-lived climate pollutants (SLCPs) are considered as air pollutants with health and environmental effects. The Norwegian Environment Agency, on behalf of the Ministry of the Environment, has performed an assessment of climate, health and environmental effects of Norwegian emissions of SLCPs and proposed measures and instruments for reducing such effects by 2030. SLCPs are in this context defined as black carbon $(\mathrm{BC})$, tropospheric ozone $\left(\mathrm{O}_{3}\right)$, methane $\left(\mathrm{CH}_{4}\right)$ and some hydrofluorocarbons (HFCs). Organic carbon (OC) and sulphur dioxide $\left(\mathrm{SO}_{2}\right)$, which contribute to cooling, can have the same emission sources as the SLCPs and have therefore also been included in the assessment. In our integrated approach to assess the mitigation possibilities for SLCPs we have identified emissions reduction possibilities which benefit both air pollution and climate change (win-win) as well as win-lose situations. Pioneering work will always be faced with challenges, and the paper describes how these were met and lists knowledge gaps. The paper outlines the methodologies developed in order to perform an analysis of measures. It shows that the choice of emission metric is strongly linked to the purpose of the analysis, and highlights the importance of $\mathrm{CO}_{2}$ reductions also for short-term climate change mitigation purposes. Further, our approach to include health effects in the cost estimates of measures is presented. Finally a presentation of mitigation strategies is given. The results are summarized in a proposed Norwegian action plan, and clearly demonstrate why it is important to perform holistic assessments of air pollution and climate change in order to best inform policy makers.

Keywords: short-lived climate pollutants, black carbon, integrated analysis, metric, measures, cost-curves, reduction strategies, policy development.
\end{abstract}




\section{Introduction}

In recent years, the climate, health and environmental benefits of reducing emissions of short-lived climate pollutants (SLCPs) have received increasing international and national attention. A report from the UN Environmental Programme (UNEP) shows that a set of emission-reducing measures aimed at SLCPs could reduce global warming by $0.5^{\circ} \mathrm{C}$ by 2050 [1]. The UNEP study also shows that at a global level, reduction of SLCPs could prevent millions of premature deaths, as well as reducing losses of wheat, rice, maize and soya crops by approximately $1-4 \%$ of the global production of these foods. Smith and Mizrahi [2] confirm the slower rate of global warming caused by emission reduction of SLCPs, but the temperature decrease is substantially less and $0.16^{\circ} \mathrm{C}$ in 2050. According to Bowerman et al. [3], early emphasis on SLCPs reduction without simultaneously reductions in $\mathrm{CO}_{2}$ may delay, but do not substantially affect the risk of crossing temperature thresholds. In order to prevent warming in the longer term, emissions of long-lived greenhouse gases such as $\mathrm{CO}_{2}$ must be reduced. Shoemaker et al. [4] emphasise the need for parallel strategies for reducing SLCPs and $\mathrm{CO}_{2}$. By implementing measures aimed at both SLCPs and long-lived greenhouse gases, a more rapid climate benefit could be obtained, thereby increasing the chances of achieving the $2^{\circ} \mathrm{C}$ target that the world's leaders have set for preventing dangerous climate change.

The Norwegian Environment Agency, on behalf of the Ministry of the Environment, has performed an integrated assessment of climate, health and environmental effects of Norwegian emissions of SLCPs, proposed measures and instruments for reducing such effects by 2030 and reviewed the need for additional monitoring of these components [5]. In this proposed action plan (Action plan), SLCPs are defined as gases and particles that contribute to warming and that have a lifetime of a few days to 15 years. These include black carbon (BC), tropospheric ozone $\left(\mathrm{O}_{3}\right)$, methane $\left(\mathrm{CH}_{4}\right)$ and some hydrofluorocarbons (HFCs). Organic carbon (OC) and sulphur dioxide $\left(\mathrm{SO}_{2}\right)$, which contribute to cooling, are often co-emitted with SLCPs and have therefore also been included. A characteristic of the climate effects of the SLCPs, with the exception of the HFCs and to a certain extent $\mathrm{CH}_{4}$, is that it matters where in the world the emissions are released. In our analysis, climate effects are defined as global warming or cooling of the atmosphere. Health effects are defined as effects on public health caused by given concentrations of one or more pollutants. Environmental effects are defined as effects on crops and forests caused by given concentrations of one or more pollutants.

The study of SLCPs is a relatively new field in public administration. The basis of scientific knowledge is still immature and has developed in parallel with work on the Action plan. A great deal of the work has therefore consisted of monitoring the research front and developing methods, emission inventories, projections and assessment of uncertainties, so as to analyse the measures. As far as we are aware, no corresponding analyses have been performed in other countries. 
This paper outlines the methodologies developed in order to perform an analysis of measures as well as results concerning climate, health and environmental effects of Norwegian emissions of SLCPs in section 2-4. In section 5 we present the framework established for the analysis of measures and ways of presenting results to stakeholders. Uncertainties are discussed in section 6 , while section 7 summarizes the lessons learned. The measures themselves are not presented in any detail in this paper, but are discussed in the Action plan [5] and in more depth in the accompanying sector report [6].

\section{Norwegian emission inventories for black carbon and organic carbon}

The first Norwegian emission inventory for $\mathrm{BC}$ and $\mathrm{OC}$ has been established in connection with the Action plan, and is documented in [7]. BC is mainly formed by incomplete combustion of fossil fuels, biofuels and biomass and is in our work defined as the light-absorbing part of fine particles (PM2.5). OC is the reflective proportion of fine particles. Together with $\mathrm{BC}, \mathrm{OC}$ represents the dominant proportion of carbonaceous particles. Figure 1 shows the emission sources of black carbon in Norway.

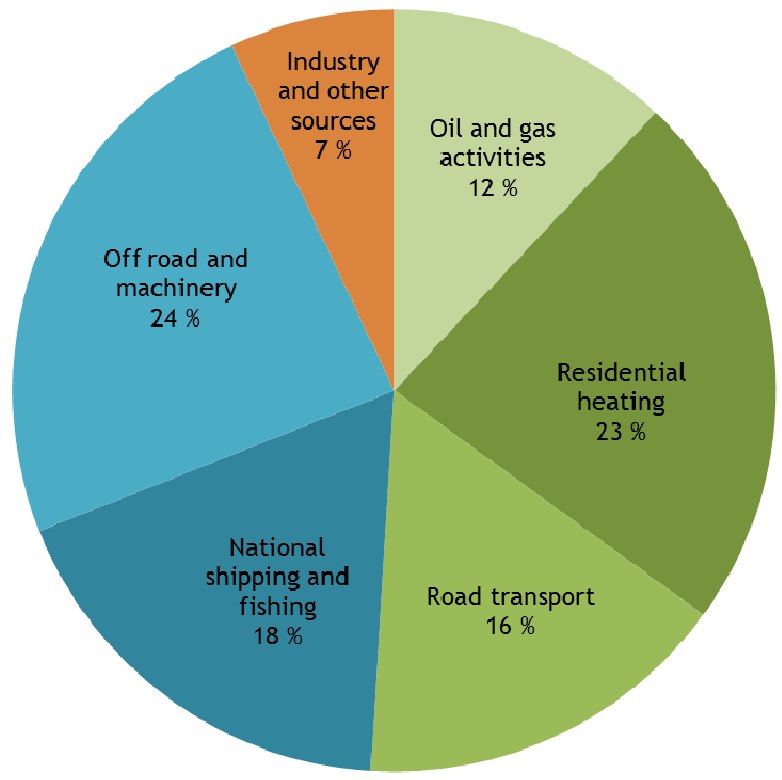

Figure 1: Distribution of sources for Norwegian 2011 emissions of black carbon $[7,8]$.

The main sources are wood burning for domestic heating and diesel engines. Total BC emissions were in 2011 approximately 5100 tons. The main source of OC emissions is residential wood-burning stoves. This source represents $83 \%$ of 
the national OC emissions. Total OC emissions were in 2011 approximately 20,000 tons. The uncertainty estimates for BC and OC emissions have not been quantified, but are assumed to be considerably higher than for the other components included in the Action plan.

\section{Calculation of climate effects in the action plan}

The combined climate effect, that is to say the sum of the warming and cooling effects, has been calculated for all the measures that have been assessed. The climate effects of the different components can be compared and summarised after conversion into $\mathrm{CO}_{2}$ equivalents $\left(\mathrm{CO}_{2 \mathrm{e}}\right)$. This is done by multiplying emissions in tons by a factor or emission metric that states the climate effect of the relevant component relative to the climate effect of a ton of $\mathrm{CO}_{2}$ with certain given assumptions. The three key assumptions are 1) the method for calculating the climate effect, typically global warming potential (GWP) or global temperature change potential (GTP); 2) the period of time over which the climate effect is calculated; and 3) the region where the emissions occur. GWP reflects all the effects on the climate that an emission has had over the entire period, while GTP gives a snapshot of the temperature response in the last year. The metrics applied in this study are based on model studies performed by Center for International Climate and Environmental Research - Oslo (CICERO) of the global climate response of Norwegian emissions of SLCPs (Hodnebrog et al. [9]).

There is no international consensus over which metrics are most suitable for analysing short-lived climate pollutants. IPCC [10] and several others state that the choice of metric depends on the purpose of the analysis. During the first commitment period of the Kyoto Protocol under UNFCCC, GWP calculated over a hundred-year period was used, regardless of where the emission occurred ("GWP100, global"). The Kyoto gases are methane, HFCs and several long-lived gases, including $\mathrm{CO}_{2}$. Our objective is to analyse the climate effects of SLCPs in the short term. As we have assessed it, "GTP10, Norway", i.e. global temperature change potential calculated ten years after the emission occurred in Norway, is the most appropriate metric for analysing measures for Norwegian emissions of SLCPs in the short term. This metric gives a snapshot of the temperature response 10 years after the emission and reflects both the short lifetime of SLCPs and the fact that the emissions occur in Norway.

A risk in using metrics to compare different climate pollutants is that this may create the impression that it does not matter which component is reduced, as long as the estimated climate effect in $\mathrm{CO}_{2}$ equivalents is the same. Using "GTP10, Norway", the emissions will only be "equivalent" in terms of temperature change ten years after emission occurred in Norway. It is particularly important to bear this in mind when the climate effect of $\mathrm{BC}$, which only stays in the atmosphere for a few days, is seemingly likened to $\mathrm{CO}_{2}$ and other long-lived greenhouse gases by a metric that focuses on the SLCPs. $\mathrm{CO}_{2}$ and other longlived gases have a lifetime in the atmosphere much longer than 10 years. The long-term effects of the long-lived gases on the climate system are thus not 
reflected in "GTP10, Norway", for example sustained global warming due to climate feedback of the carbon cycle, deep ocean temperature change, and other factors. There is not one, single metric that describes the climate effects of both short-lived and long-lived components in an appropriate manner.

\section{Results of the climate, health and environmental effects}

The following sections focus on the climate and health effects related to SLCP emissions in Norway. It has not been possible to quantify the effect SLCPs have on crops and forests. The environmental effects are however anticipated to be small, partly based on an analysis of the level of nationally produced ozone (Hodnebrog et al. [9]).

\subsection{Significant climate effects of Norwegian emissions of black carbon and methane in the short term}

The overall climate effect of Norwegian emissions of SLCPs was 35 million tons $\mathrm{CO}_{2 \mathrm{e}(\mathrm{GTP} 10, \text { Norway) }}$ in 2011, distributed as shown to the left in Figure 2. The figure also includes the climate effect of $\mathrm{OC}$ and $\mathrm{SO}_{2}$ which is co-emitted with SLCPs from certain sources.

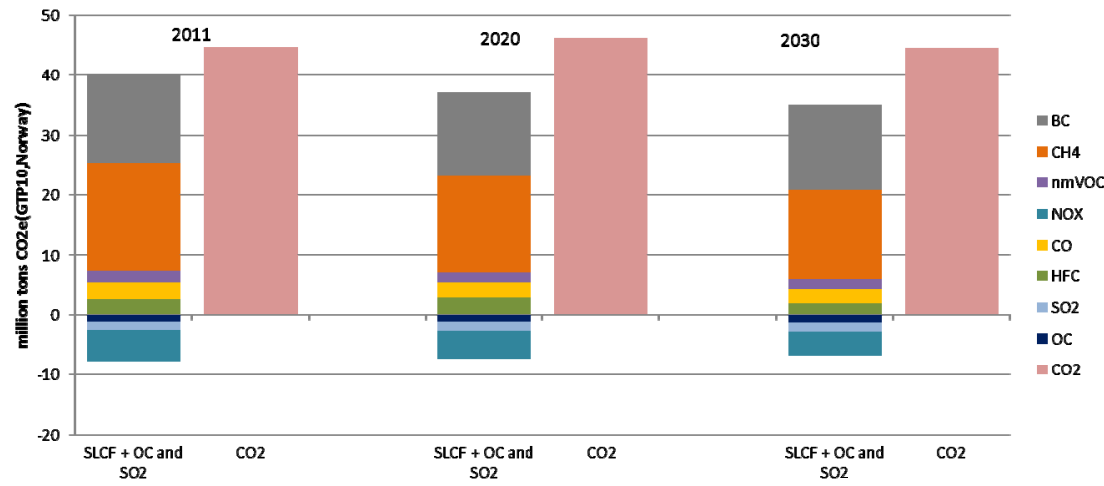

Figure 2: Global climate effect of SLCPs, $\mathrm{OC}$ and $\mathrm{SO}_{2}$ compared with that of $\mathrm{CO}_{2}$ in 2011,2020 and 2030.

Figure 2 shows that the warming effect of Norwegian emissions of SLCPs is clearly largest for methane, followed by $\mathrm{BC}$. The warming effect of the ozone precursors $\mathrm{CO}$ and nmVOCs, as well as HFCs, is considerably less. The ozone precursor $\mathrm{NO}_{\mathrm{x}}$, like $\mathrm{OC}$ and $\mathrm{SO}_{2}$, has a cooling effect and are plotted below zero on the $\mathrm{y}$ axis. $\mathrm{NO}_{\mathrm{x}}$ emissions have a cooling effect in a ten-year perspective primarily because $\mathrm{NO}_{\mathrm{x}}$ leads to a reduction of $\mathrm{CH}_{4}$ in the atmosphere. OC and $\mathrm{SO}_{2}$ emissions form particles that cause cooling because they reflect the sunlight. 


\subsection{Important to reduce both SLCPs and CO2 in the short term}

In a 100 -year perspective, $\mathrm{CO}_{2}$ and other long-lived greenhouse gases dominate the climate effects. The climate effects of the SLCPs are limited in a 100-year perspective [5]. In order to achieve a long-term reduction in warming, it is therefore most important to reduce the emissions of $\mathrm{CO}_{2}$ and other long-lived greenhouse gases.

Figure 2 compares the climate effect of SLCPs with that of $\mathrm{CO}_{2}$ in a ten-year

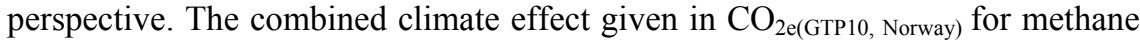
and $\mathrm{BC}$ in 2011 was approximately $70 \%$ of the climate effect of Norwegian $\mathrm{CO}_{2}$ emissions. In a ten-year perspective, the climate effect of SLCPs is considerable, but even in a short-term perspective, the climate effect of Norwegian $\mathrm{CO}_{2}$ emissions in 2011 alone was greater than the overall climate effect of all Norwegian emissions of SLCPs. The short-term climate effect of $\mathrm{CO}_{2}$ emissions becomes even more important relative to the effect of SLCPs for the years 2020 and 2030. This indicates that $\mathrm{CO}_{2}$ reduction is also important in the short term. From a global warming point of view, it is therefore important to ensure large, rapid reductions in emissions of $\mathrm{CO}_{2}$. Measures aimed at SLCPs cannot replace $\mathrm{CO}_{2}$ measures in mitigate climate change in either the short or long term. But reduced Norwegian emissions of SLCPs, and especially methane and BC, will reinforce the global climate benefits of rapid reductions in $\mathrm{CO}_{2}$ emissions.

\subsection{Norway's BC emissions are of significance for the Arctic}

Norway's BC emissions have approximately a 1.5 times higher climate effect per ton than the global average and may contribute to melting in the Arctic (Hodnebrog et al. [9]). This is because the albedo effect of Norwegian BC emissions is high compared to the global average due to our proximity to the Arctic. The same applies to other countries close to the polar regions or other snow- and ice-covered areas such as the Himalayas.

\subsection{A reduction in Norway's $\mathrm{BC}$ emissions could give positive health effects in Norway}

Reducing Norway's BC emissions could also give health benefits, since the current high level of fine particles in cities and urban settlements may be detrimental to public health. Due to BC's climate effects in the Arctic and its negative health effects, reduction of these emissions should be given special consideration.

\subsection{No climate benefit from $\mathrm{NO}_{\mathrm{x}}$ reductions}

In a short-term perspective, reducing emissions of the ozone precursor $\mathrm{NO}_{\mathrm{x}}$ will contribute to warming. In the longer term, e.g. 100 years, $\mathrm{NO}_{\mathrm{x}}$ emissions have a minimal climate effect. $\mathrm{NO}_{\mathrm{x}}$ reductions will however give health and environmental benefits. In cities and urban settlements, the levels of $\mathrm{NO}_{2}$ may be detrimental to public health. $\mathrm{NO}_{\mathrm{x}}$ also contributes to the creation of ozone, which 
is hazardous to health. The environmental effect of nationally produced ozone is limited. International collaboration is important for reducing levels of $\mathrm{NO}_{\mathrm{x}}$ and ozone in Norway, since a high proportion of these components are long-range transboundary air pollutants.

\section{Results on the analysis of measures}

The objective of this part of the study is to perform an integrated assessment of climate, health and environmental effects of Norwegian emissions of SLCPs and to propose measures and instruments to reduce such effects by 2030 . No target for emission reductions has been defined.

\subsection{Framework for analysing measures and instruments}

The analysis is limited to emissions covered by the Norwegian emission inventory as published by the Norwegian Environment Agency and Statistics Norway [8]. A number of " $\mathrm{CO}_{2}$ measures" will also reduce emissions of SLCPs, for example traffic-reducing measures or a transition to more environmentallyfriendly vehicles or renewable energy, but the focus for this analysis is to identify emission reductions that are in addition to the reductions that follow from $\mathrm{CO}_{2}$ measures. Thus, the analysis does not give an overview of the complete reduction potential for Norwegian emissions of SLCPs.

We have targeted our measures at emission sources where the reduction potential for SLCPs is large. Most of our measures are aimed at $\mathrm{BC}$ and $\mathrm{CH}_{4}$, which are the SLCPs with the largest short-term climate effect (Figure 2). The reduction potential of the measures is described in relation to the emission developments we expect on the basis of adopted policies; a so-called reference scenario. For some measures, there may be a trade-off between desired climate benefit and positive health and environmental effects. As mentioned above, for example, $\mathrm{NO}_{\mathrm{x}}$ reductions cause short-term warming, but give health and environmental benefits. Our objective has been to reduce warming in the short term without significant, adverse health and environmental effects. We have therefore not assessed measures that target $\mathrm{NO}_{\mathrm{x}}$ specifically, but co-emitted $\mathrm{NO}_{\mathrm{x}}$ is included.

Within this framework, the available basis of data and knowledge has been a limitation in terms of which measures it has been possible to assess, and we have identified areas for further investigations. Accordingly, this analysis is intended to illustrate mitigation options targeting SLCPs and further work may be necessary to identify better measures, as well as to design the assessed measures appropriately.

\subsection{Emission reductions and cost-efficiency of identified measures}

The combined climate effect, i.e. the sum of the warming and cooling effects, has been calculated for all measures. Cooling components such as co-emitted $\mathrm{NO}_{\mathrm{x}}, \mathrm{OC}$ and $\mathrm{SO}_{2}$ cause warming when they are reduced. This is particularly important to take into account for emission sources that contain a high 
proportion of cooling components, such as burning wood. The share of OC in a ton of particles from road transport emissions for example is much lower than from wood burning, so that the combined climate benefit of reducing a ton of BC emissions from road transportation is larger than for a ton of $\mathrm{BC}$ emissions from burning wood and other biomass. The implication is that measures aimed at emission sources that also emit large quantities of cooling components are not necessarily good climate measures under all circumstances.

We have assessed the combined climate effect, as well as health and environmental effects, for 18 non-overlapping measures, that is to say measures that genuinely complement each other because they reduce different emissions. Measures have been identified in six sectors (petroleum, industry, residential heating, transport, agriculture and HFCs in products) that together accounted for $83 \%$ of all Norwegian emissions of SLCPs in 2011. The measures and their assessed characteristics are shown in table 1. The four assessed characteristics included in this analysis are cost effectiveness, climate effect, health effect and emission reduction effectiveness. The latter is qualitatively determined and based on expert judgment of how realistic it is to achieve the estimated emission reductions through the most relevant instrument or combination of instruments. Emission reduction effectiveness is ranked qualitatively as high, moderate or low. In general, regulatory requirements are considered to be effective instruments, while raising awareness through public information and outreach are typically considered to be less effective. A combination of instruments is often necessary to trigger a measure. For example targeted information about financial support schemes could increase the emission reduction effectiveness of financial instruments. Cost effectiveness and climate and health effects of the measures have also been assessed as high (Dark brown background in table 1), moderate (Medium brown) or low (Light brown) on the basis of an interrelated evaluation (Cost effectiveness (NOK/ton $\mathrm{CO}_{2 \mathrm{e}(\mathrm{GTP} 10 \text {, Norway) }} \mathrm{H}<0, \mathrm{M}=0-600$,

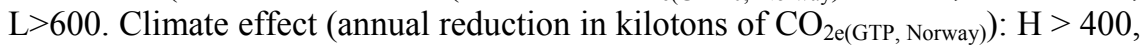
$\mathrm{M}=200-400$ and $\mathrm{L}<200$. Health effect (annual health benefit in million NOK): $\mathrm{H}>100, \mathrm{M}=50-100, \mathrm{~L}<50$ ). In the column for instruments in table 1 the shading describes the degree of emission reduction effectiveness. No consideration has been given to whether the values for cost effectiveness and climate and health effects are low, moderate or high in relation to other analyses. The assessment of all measures has been based on one chosen designed. It would be possible to scale the measures differently.

The climate effect of the 18 measures is 4.3 million tons of $\mathrm{CO}_{2 \mathrm{e}(\mathrm{GTP} 10 \text {,Norway) }}$ on average per year, i.e. approximately $12 \%$ of the total emissions of SLCPs in 2011 (Figure 2). The largest emission reductions are $\mathrm{BC}$ reductions, followed by methane and HFC reductions, both of which are regulated under the Kyoto Protocol. The combined effect of BC and OC reductions corresponds to $40 \%$ of the reduction potential of the 18 measures. Correspondingly, the combined effect of the reduction of the Kyoto gases methane and HFC is also $40 \%$. The final $20 \%$ comes from the reductions in long-lived greenhouse gases $\mathrm{CO}_{2}$ and $\mathrm{N}_{2} \mathrm{O}$ $(13 \%)$ and the remaining SLCPs $\left(\mathrm{NO}_{\mathrm{x}}, \mathrm{CO}\right.$ and $\left.\mathrm{nmVOC}\right)$ and $\mathrm{SO}_{2}(7 \%)$. 


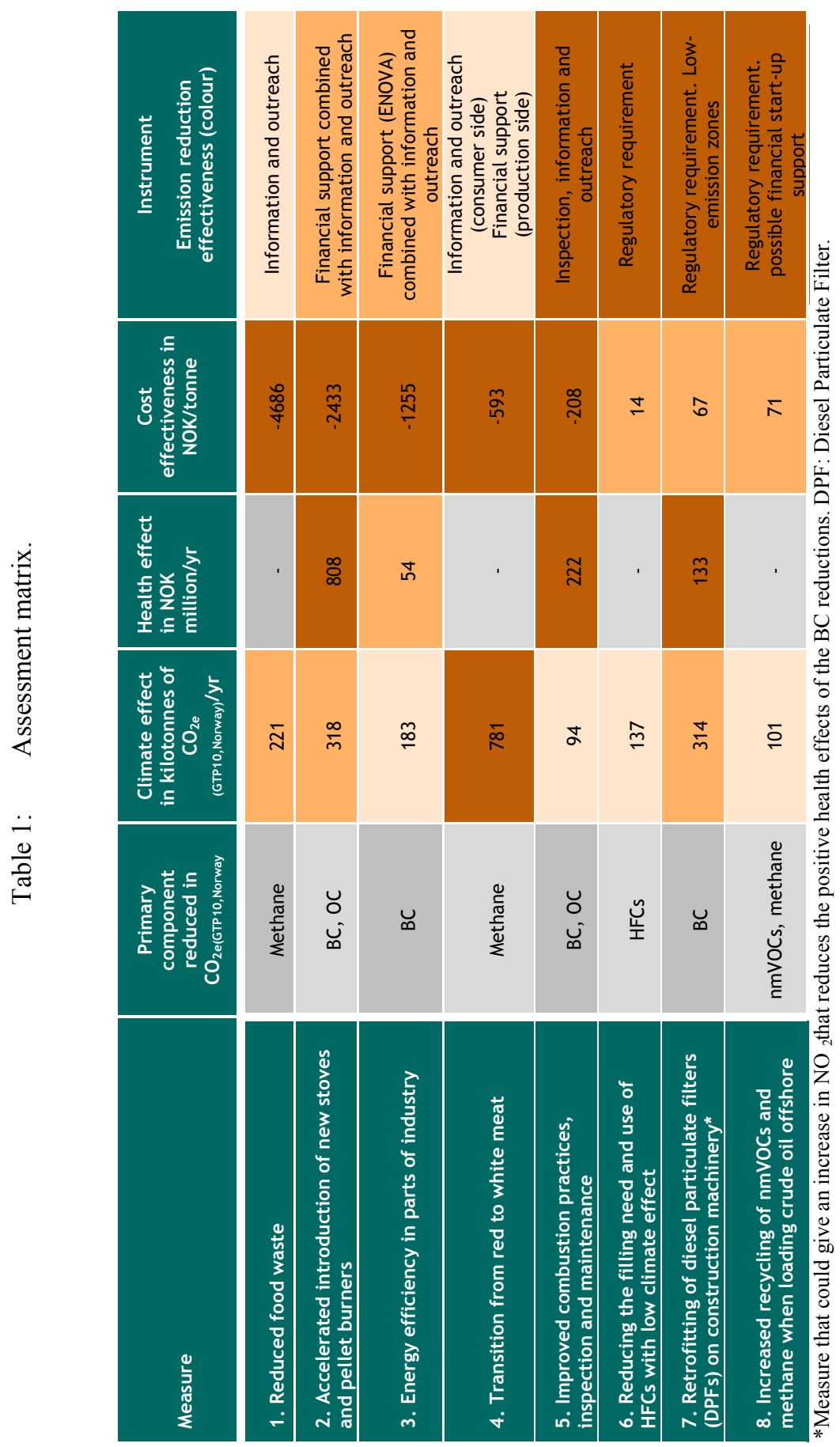




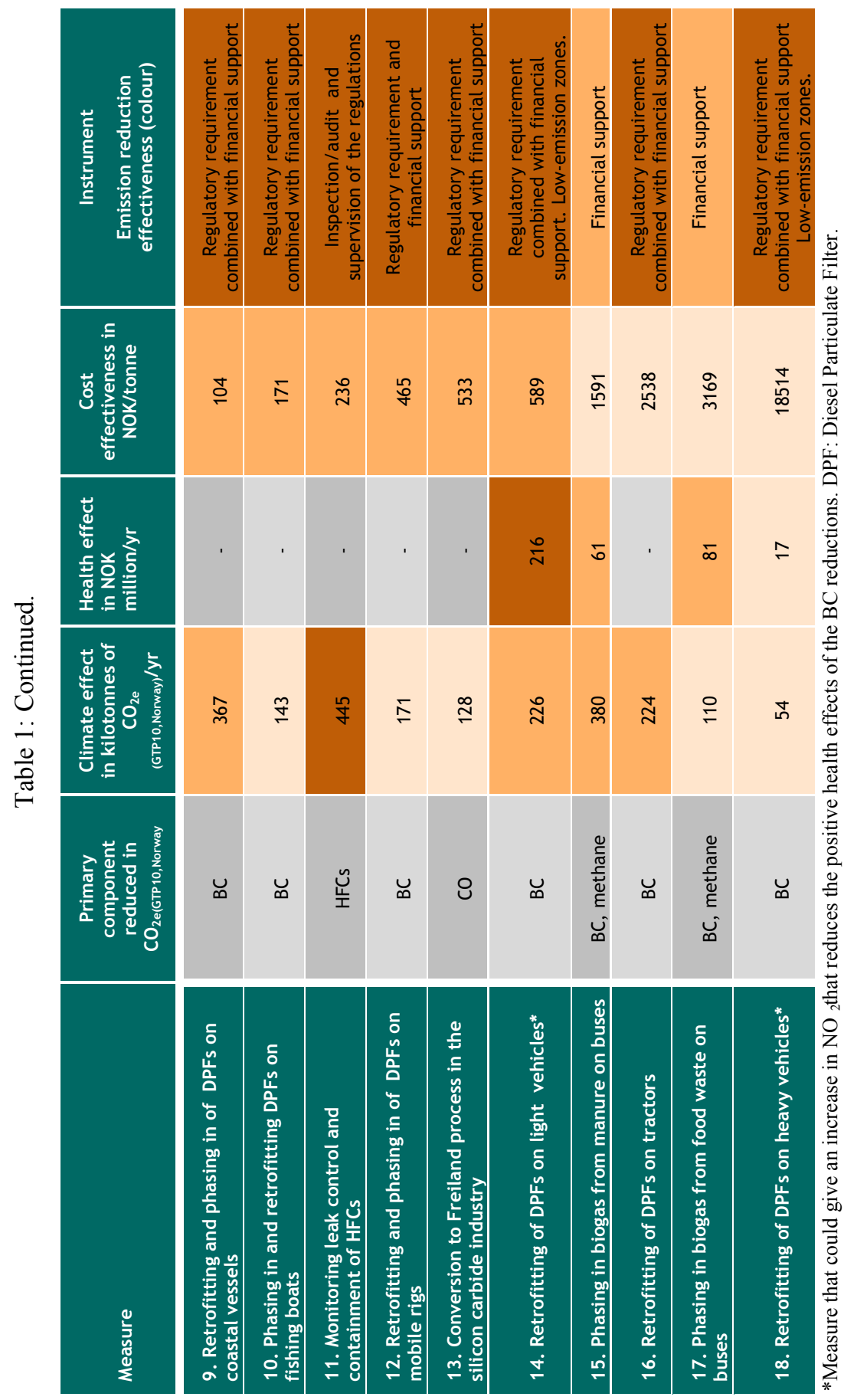

WIT Transactions on Ecology and The Environment, Vol 183, (C) 2014 WIT Press www.witpress.com, ISSN 1743-3541 (on-line) 
In assessing these 18 measures, we have emphasised the cost per reduced ton of $\mathrm{CO}_{2 \mathrm{e}(\mathrm{GTP} 10,}$, Norway), so-called cost effectiveness. The cost effectiveness of the measures has been calculated in line with the Norwegian Ministry of Finance's guidelines for socio-economic analysis. The cost of the measures includes valued health effects when relevant, i.e. health benefits measured in NOK have been deducted from the cost of the measure. Eight of the 18 measures have health effects. The combined health benefits of these eight measures average NOK 1.6 billion a year. We have not had the data required to value the effects on forest and crops (environmental effects) in the same way as for health effects, but these are believed to have negligible significance for the conclusions of the analysis.

In Figure 3, the measures have been ranked by increasing cost per reduced ton of $\mathrm{CO}_{2 \mathrm{e}(\mathrm{GTP} 10 \text {, Norway), }}$ i.e. by declining cost effectiveness. The annual accumulated reduction potential for the measures is summarised along the $\mathrm{x}$ axis. Thus the figure shows what reduction potential can be achieved for a given cost effectiveness (y axis). The cost effectiveness is also shown without health benefit (crosses) to demonstrate the significance health benefits have for cost effectiveness. The ranking of most measures changes when the health effect is no longer included.

Figure 3 indicates that cost effectiveness becomes significantly poorer from around NOK 600 (approximately US\$100) per reduced ton of $\mathrm{CO}_{2 \mathrm{e}(\mathrm{GTP} 10, \text { Norway) }}$ for the curve that includes health benefits (squares). Four of the measures are

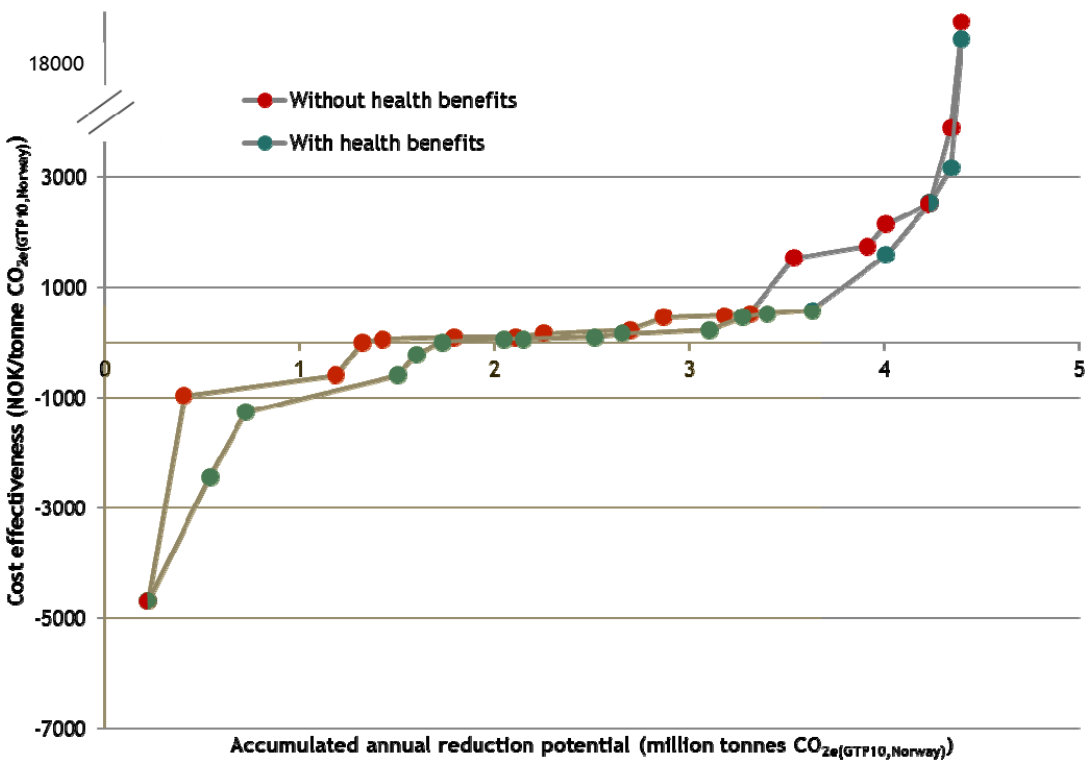

Figure 3: Cost effectiveness and cumulative annual reduction potential for the 18 non-overlapping measures. 
calculated to have cost effectiveness considerably poorer than NOK 600 per ton of $\mathrm{CO}_{2 \mathrm{e}(\mathrm{GTP} 10 \text {,Norway) }}$ and are outside the grey zone. The calculations show in addition that the eight measures with health effects become considerably more expensive if the health effects are not included. Five measures have been calculated to cost less than NOK 0 per reduced ton of $\mathrm{CO}_{2 \mathrm{e}(\mathrm{GTP} 10 \text {, Norway). For two }}$ of the measures this is due to the large health benefits. For the other three measures this is primarily due to cost savings.

\subsection{Emission reduction strategies}

Based on four assessed characteristics we have grouped the measures to form six different emission reduction strategies named (1) Cost-effective, (2) Cost- and emission reduction effective, (3) Cost- and emission reduction effective with moderate/high climate effect, (4) Cost- and emission reduction effective with moderate/high health effect, (5) Cost- and emission reduction effective with both moderate/high climate effect and moderate/high health effect and last (6) a strategy for SLCPs Regulated under the Kyoto Protocol. In this way we have given the policy makers a convenient way of choosing measures for implementation depending on their priorities.

The framework we have developed makes it possible to plot measures according to their main attributes. Figure 4 illustrates how such a graphical

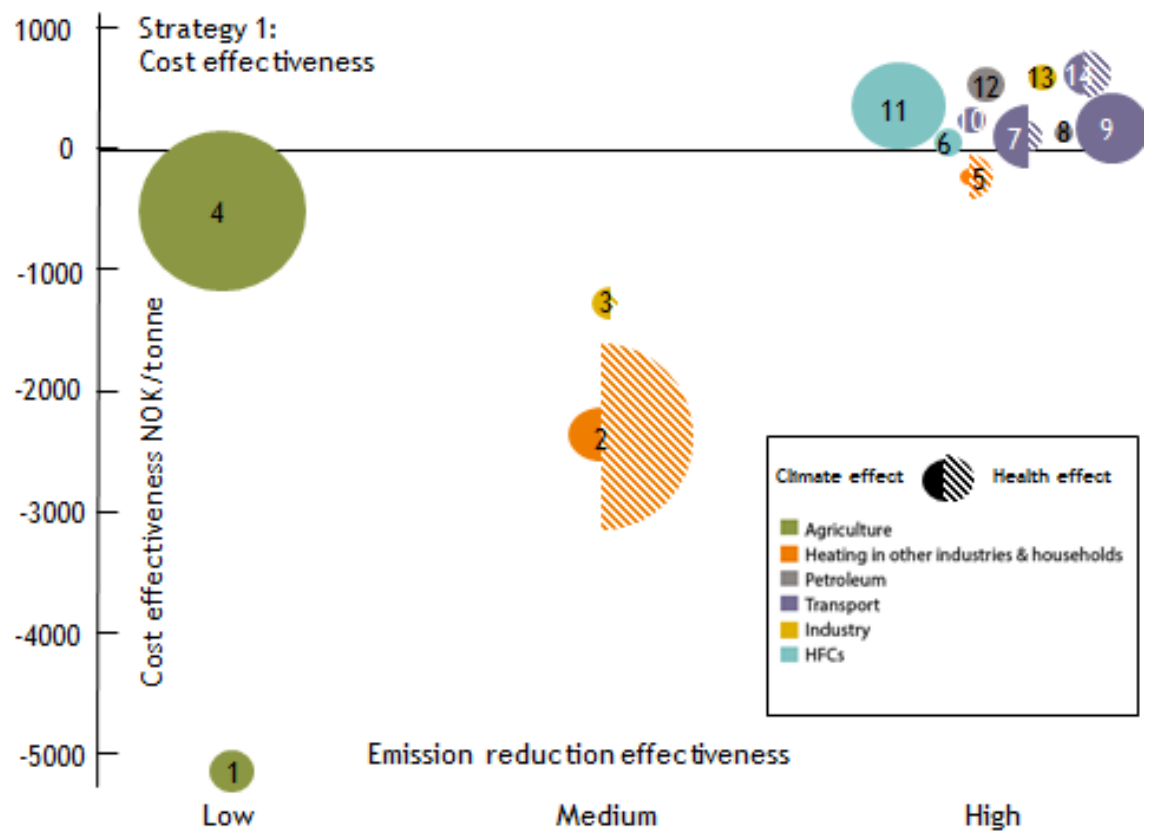

Figure 4: Graphical presentation of measures included in reduction strategy 1 for cost effective measure including health effects. 
presentation might look like for an emission reduction strategy that includes the 14 cost effective measures in this analysis, i.e. reduction strategy 1. Measures are numbered as in table 1 and according to their cost effectiveness. The position of the circles visualizes the cost effectiveness and emission reduction effectiveness of individual measures. The size of the circles indicates low, moderate or high climate and health effects. Filled circles represent the climate effect, while hatched circles represent the health effect.

\section{Uncertainties}

As with other analyses of measures, there are uncertainties associated with this analysis. Such uncertainties are i.a. associated with the cost of measures, the technological maturity of several largely untested technologies and the degree to which instruments can be introduced so as to obtain the measures' full technical reduction potential. For instance, several measures in the transport sector include diesel particulate filters for reducing $\mathrm{BC}$ emissions, but there is an uncertainty to which extent these lead to an increase in fuel consumption and $\mathrm{NO}_{2}$ emissions. Some other types of uncertainty derive from the basis of scientific knowledge being immature and having developed in parallel with the work on the action plan. These uncertainties are mainly associated with emission inventories and the calculation of emission reductions and climate, health and environmental effects. The uncertainties are generally largest for $\mathrm{BC}$ and to some extent also $\mathrm{OC}$ and $\mathrm{SO}_{2}$. For health effects, the uncertainty is largest for $\mathrm{BC}$ reductions, which have been valued in principle as PM10 reductions.

There are also uncertainties related to the metric (as a result of uncertainty in modelling) and the choice of metric. Sensitivity analyses with various metrics indicate that the climate effect of the measures is generally reduced if the time horizon is increased from 10 to 100 years. The wood-burning measures are primarily health measures in the long term (little climate effect).

Even though there are un-quantified uncertainties related to the climate effect of measures, we consider all the assessed measures as climate measures in the short term. The measures will be more expensive if the climate effect is overestimated. We assume that uncertainty regarding the health effect is considerably less than for the climate effect. For the eight measures that have a health effect in this analysis, we cannot judge whether the health effect is overor underestimated.

\section{Lessons learned}

We have made an integrated assessment of measures based on climate, health and environmental effects. In this way we have been able to show that the climate effect of SLCPs are less but comparable to that of $\mathrm{CO}_{2}$ in the short-term and highlight conflicting targets and win-win situations between climate- health and environmental goals. The costs of the measures are also better reflected because the health effects are included. The basis for decision making is therefore more complete. We have also identified a number of reduction 
possibilities that cannot currently be analysed quantitatively because of a lack of basic data and knowledge. We see a need to obtain more information, so as to assess whether there may be attractive measures among these reduction possibilities. Reductions of SLCPs in traditional $\mathrm{CO}_{2}$ measures should also be looked at, in order to assess how emissions of SLCPs can be reduced most effectively. Given the necessity for rapid climate mitigation, this should not hamper implementation of identified SLCPs measures. The study revealed a need to strengthen the planned national monitoring of black carbon, organic carbon and methane, there is a further need for local monitoring of black carbon.

Norway currently has national climate targets in connection with the greenhouse gases regulated by the Kyoto Protocol under the UN Framework Convention on Climate Change (UNFCCC). The obligations are linked to longterm temperature stabilisation. Consideration could be given to establishing a short-term target for reducing the rate of warming, in addition to the present long-term targets. Any short-term target should cover all the components that have a temperature response in the short term, i.e. both SLCPs and $\mathrm{CO}_{2}$ and other long-lived components. Since several of the SLCPs are also air pollutants, it is important to see the achievement of targets for climate change and air pollution in relation to each other. When establishing targets for climate and air pollution, one should consider taking the mutual effects these have on each other into consideration.

Public administration involves many decisions influencing both climate change and air pollution. This work is done by means of various national and international initiatives, and there are a number of different groups involved. There is therefore a need for improved coordination, both within public administration and in relation to external organizations in order to ensure consistent and environmentally friendly policy making.

Norway already participates in a number of global and regional initiatives aiming to reduce emissions of SLCPs. The regional initiatives include the LRTAP Convention, the EU, the Arctic Council and the Nordic Council. The global initiatives include the Climate and Clean Air Coalition (CCAC), the Montreal Protocol (the inclusion of HFCs is being considered), the Climate Convention (methane and HFCs), the UN International Maritime Organisation (IMO) and the Global Methane Initiative. Countries should work actively to establish an international definition of and measurement methods for BC, as well as guidelines for reporting of emissions. There is also a need to harmonise international monitoring of the SLCPs.

Binding international collaboration to reduce $\mathrm{BC}$ emissions especially, since methane and HFCs are covered by the Kyoto Protocol, and ozone precursors are covered by the Gothenburg Protocol, should be considered. In the short term, this should occur through regional initiatives such as the LRTAP and possibly the Arctic Council. In the longer term, this could possibly be done through the Climate Convention or other global initiatives. Because of the regional nature of the SLCPs, further consideration must be given to whether the Climate Convention is a suitable arena. 


\section{References}

[1] UNEP/WMO, 2011, Integrated assessment of black carbon and tropospheric ozone, Summary for policymakers, United Nations Environment Programme (UNEP), Nairobi, Kenya, http://www.unep.org /dewa/Portals/67/pdf/ BlackCarbon_report.pdf

[2] Smith, S. J., and A. Mizrahi (2013), Near-term climate mitigation by short-lived pollutants, Proceedings of the National Academy of Sciences of the United States of America, 110 (35), pp. 14202-14206.

[3] Bowerman, N. H. A, Frame, D. J., Huntingford, C. H., Lowe, J. A., Smith, S. M. \& Allen, M. R., The role of short-lived climate pollutants in meeting temperature goals. Nature Climate Change, 3, pp. 1021-1024, 2013.

[4] Shoemaker, J. K., Schrag, D. p., Molina, M. J. \& Ramanatan, V., What Role for Short-Lived Climate Pollutants in Mitigation Policy? Science, 342, 1323-1324, 2013.

[5] Norwegian Environment Agency, 2013, Proposed Action plan for Norwegian emissions of short-lived climate pollutants, M89/2013 (In Norwegian), http://www.miljodirektoratet.no/no/Publikasjoner/2013/ Desember-2013/Forslag-til-handlingsplan-for-norske-utslipp-av-kortlevdeklimadrivere/

[6] Norwegian Environment Agency, 2013, Sector report to Proposal to Action plan for Norwegian emissions of short lived climate pollutants, M90/2013 (In Norwegian), http://www.miljodirektoratet.no /no/Publikasjoner/2013/Desember-2013/Underlagsrapport-til-Forslag-tilhandlingsplan-for-norske-utslipp-av-kortlevde-klimadrivere/

[7] Statistics Norway, 2013, Emissions of black carbon and organic carbon in Norway 1990-2011, Document 13/2013, http://www.ssb.no/natur-ogmiljo/artikler-og-publikasjoner/_attachment/107884?_ts=13dfd568678

[8] Klif/Statistics Norway (2013), http://www.miljostatus.no/miljostatus.no, http://www.ssb.no/

[9] Hodnebrog, Ø., Aamaas, B., Berntsen, T. K., Fuglestvedt, J. S., Myjre, G., Samset, B. H., Søvde, A, 2013, Klimaeffekt av norske utslipp av kortlevde klimadrivere, CICERO report to Klif (In Norwegian), http://www.miljodirektoratet.no/Global/dokumenter/Nyheter\%20vedlegg/ klimaeffektavnorskeutslipp_CICERO_sluttrapport.pdf

[10] IPCC, 2013, Climate Change 2013: The Physical Basis. Working Group I contribution to the IPCC Fifth Assessment Report (WG1 AR5), http://www.ipcc.ch/report/ar5/wg1/

[11] Ministry of Finance, 2013, St.mld nr 12 (2013), Perspektivmeldingen, Ministry of Finance (In Norwegian), http://www.regjeringen.no/nb /dep/fin/dok/regpubl/stmeld/2012-2013/meld-st-12-20122013.html?regj_ oss $=1 \& \mathrm{id}=714050$ 